\title{
Anticholinergic burden, oral hygiene practices, and oral hygiene status-cross-sectional findings from the Northern Finland Birth Cohort 1966
}

\author{
Antti Tiisanoja ${ }^{1,2}$ (D) Anna-Maija Syrjälä ${ }^{1,2} \cdot$ Vuokko Anttonen $^{2,3} \cdot$ Pekka Ylöstalo ${ }^{1,2}$ \\ Received: 14 October 2019 / Accepted: 29 July 2020 / Published online: 3 August 2020 \\ (C) The Author(s) 2020
}

\begin{abstract}
Objectives To study the association between anticholinergic burden and oral hygiene practices and oral hygiene status among 46year-old people.

Materials and methods The study included 1945 participants from the Northern Finland Birth Cohort 1966 (NFBC1966), who had a complete dental status. The participants underwent clinical medical and dental examinations, and their medication data were gathered by combining self-reported drug use with information from the National Prescription Register. Anticholinergic burden was measured using nine previously published anticholinergic scales. Oral hygiene practices were assessed with toothbrushing frequency and oral hygiene status with the presence of visible dental plaque. Poisson regression with robust variance estimation and negative binomial regression models were used to estimate relative risks (RR).

Results Thirty percent of the participants reported brushing their teeth twice a day and about $25 \%$ of their teeth had dental plaque on them. Fifteen percent of the participants used at least one anticholinergic drug or had an anticholinergic burden according to the nine anticholinergic scales. After adjustments for confounding factors, the RRs of anticholinergic burden varied between 0.95 and 1.11 for toothbrushing frequency. Anticholinergic burden (according to Anticholinergic Activity Scale, Anticholinergic Cognitive Burden, Chew's scale) was associated statistically significantly with the number of teeth with dental plaque. For the three scales, RRs varied from 1.24 to 1.50 .
\end{abstract}

Conclusions Anticholinergic burden associated with poor oral hygiene.

Clinical relevance The findings stress the importance of providing oral hygiene instructions and prophylactic measures to patients taking anticholinergic drugs.

Keywords Adults $\cdot$ Anticholinergic drugs $\cdot$ Medication $\cdot$ Dental plaque $\cdot$ Toothbrushing $\cdot$ Oral hygiene

Electronic supplementary material The online version of this article (https://doi.org/10.1007/s00784-020-03485-0) contains supplementary material, which is available to authorized users.

Antti Tiisanoja

antti.tiisanoja@oulu.fi

1 Periodontology and Geriatric Dentistry, Research Unit of Oral Health Sciences, University of Oulu, P.O BOX 5000, FI-90014 Oulu, Finland

2 Medical Research Center Oulu, Oulu University Hospital and University of Oulu, Oulu, Finland

3 Cariology, Endodontology and Paediatric Dentistry, Research Unit of Oral Health Sciences, University of Oulu, P.O BOX 5000, FI-90014 Oulu, Finland

\section{Introduction}

Good oral hygiene is a major preventive measure against common oral diseases, such as dental caries and periodontal diseases, and it is achieved by brushing teeth twice a day with toothpaste and cleaning the interdental region once a day [1]. Despite this relatively easily achievable goal, many people do not manage to implement sufficient oral hygiene in their daily lives.

Previous studies have shown that multiple sociodemographic and health-related factors, such as income and education level [2], gender [3], unhealthy lifestyle [4], and mental disorders $[5,6]$ are associated with the quality of oral hygiene. Interestingly, little is known about the effects of medication on oral hygiene, although it has been 
speculated that drugs could have an impact on oral hygiene through detrimental effects on cognitive or physical functioning [7], or by reducing the rinsing effect of saliva [8].

One medication group that could affect oral hygiene is drugs with anticholinergic properties. This group includes several different drug classes with variation in their indications and anticholinergic potency, for example oxybutynin (urinary incontinence), quetiapine (antipsychotic), and citalopram (antidepressant) [9]. Cumulative exposure to these drugs and their overall anticholinergic effect can be measured with anticholinergic burden scales [9], which identify and score drugs with anticholinergic properties by combining expert opinions, literature reviews, and laboratory measures [9].

Anticholinergic burden has previously been associated with impaired cognitive [10] and physical functioning [9], and with hyposalivation [11]. Based on these findings, it is reasonable to assume that anticholinergic drugs affect oral hygiene. Thus, this paper aimed to study whether anticholinergic burden is associated with oral hygiene practices or oral hygiene status with a hypothesis that individuals with anticholinergic burden have poorer oral hygiene than those without anticholinergic burden.

\section{Materials and methods}

\section{Participants}

The Northern Finland Birth Cohort 1966 (NFBC1966) originally included all children who were from the two northern provinces of Finland and whose expected date of birth was in the year $1966(n=12,231)$ [12]. In 2012-2013, individuals living at a convenient distance from the city of Oulu (max. $100 \mathrm{~km}$ ) were invited to participate in a voluntary 46-year follow-up study $(n=3150)$. About $62 \%$ of the invited individuals took part in a clinical oral and medical follow-up examination $(n=1962)$. The final study population included the participants with a complete dental status $(n=1945)$. A written consent for the study was given by all the participants and the study protocol was approved by the Ethical Committee of the Northern Ostrobothnia Hospital District (2/2012). The current study followed the STROBE (Strengthening the Reporting of Observational Studies in Epidemiology) guidelines.

\section{Lifestyle and general health data}

Prior to taking part in the clinical examinations, the cohort members received a questionnaire via post, which included questions about lifestyle, general health, and health behaviours. Questions covered topics such as diagnosed diseases and smoking history, and eating habits. Information from the questionnaire was further complemented with data from the official registers of Oulu University Hospital and the National Institute for Health and Welfare.

\section{Medication and anticholinergic burden}

Each participant's self-reported prescription drug use was verified with information obtained from the National Prescription Register of the Social Insurance Institute of Finland and the drugs were identified using the Anatomical Therapeutic Chemical (ATC) classification system [13].

Anticholinergic burden from regularly used drugs was measured for each participant using nine different anticholinergic rating scales: Anticholinergic Activity Scale (AAS) [14], Anticholinergic Burden Classification (ABC) [15], Anticholinergic Cognitive Burden (ACB) [16], Anticholinergic Drug Scale (ADS) [17], Anticholinergic Load Scale (ALS) [18], Anticholinergic Risk Scale (ARS) [19], Chew's scale [20], Clinician-Rated Anticholinergic Scale (CrAS) [21], and Durán's scale (Durán) [22]. An overview of the scales is presented in Table 1 and a list of all identified anticholinergic drugs is given in Online Resource 1.

All nine anticholinergic scales identify and score drugs with anticholinergic properties by combining expert opinions, literature reviews, and laboratory measures (Table 1). The scales share a similar scoring system, in which the drugs are scored according to their anticholinergic activity and the anticholinergic burden is determined by summing the drugs' scores. For further information about the anticholinergic scales, the authors recommend a recent systematic review by Villalba-Moreno and colleagues [23]. Anticholinergic burden was used in the analyses both as categorical variable (yes/no) and continuous variable to depict total anticholinergic burden.

\section{Clinical oral examination}

All the oral examinations were carried out following a standardized study protocol by seven trained and calibrated dentists. The examinations consisted of cariological, periodontal, and oral physiological segments that have been presented in detail earlier [24]. The window of time for the examinations was between April 2012 and June 2013 and therefore training and calibration of the dentists' study were repeated every 3 months. Clinical oral examinations were performed in a dental office with modern dental unit with an oral mirror, WHO ball-pointed gingival probe, and fibre-optic transillumination. During the field phase, each examiner re-examined 10 participants 1 month after the previous examination in order to assess intraexaminer agreement, and a gold-standard dentist performed a parallel examination for about seven participants of each examiner to assess interexaminer agreement. While attending the clinical oral examination, the participants also responded to a computer-aided dental survey. 
Table 1 Overview of nine anticholinergic rating scales

\begin{tabular}{|c|c|c|c|c|}
\hline Scale & $\begin{array}{l}\text { Basis for identification/ } \\
\text { scoring of anticholinergic } \\
\text { drugs }\end{array}$ & $\begin{array}{l}\text { Number of } \\
\text { anticholinergic } \\
\text { drugs included }\end{array}$ & Scoring & Grading \\
\hline Anticholinergic Activity Scale (AAS) & $\mathrm{A}, \mathrm{B}, \mathrm{C}$ & 99 & $0-4$ & $\begin{array}{l}\text { M: } 1-3, \\
H: \geq 4\end{array}$ \\
\hline $\begin{array}{l}\text { Anticholinergic Burden Classification } \\
\text { (ABC) }\end{array}$ & $\mathrm{A}, \mathrm{C}$ & 27 & $0-3$ & $\begin{array}{l}\text { M: } 1-2, \\
H: \geq 3\end{array}$ \\
\hline $\begin{array}{l}\text { Anticholinergic Cognitive Burden } \\
\text { Scale (ACB) }\end{array}$ & A, B & 88 & $0-3$ & $\begin{array}{l}\text { M: } 1-2, \\
H: \geq 3\end{array}$ \\
\hline Anticholinergic Drug Scale (ADS) & $\mathrm{A}, \mathrm{B}, \mathrm{C}$ & 117 & $0-3$ & $\begin{array}{l}\text { M: } 1-2, \\
H: \geq 3\end{array}$ \\
\hline Anticholinergic Load Scale (ALS) & A, B & 49 & $0-3$ & $\begin{array}{l}\text { M: } 1-2, \\
H: \geq 3\end{array}$ \\
\hline Anticholinergic Risk Scale (ARS) & $\mathrm{A}, \mathrm{B}$ & 49 & $0-3$ & $\begin{array}{l}\text { M: } 1-2, \\
H: \geq 3\end{array}$ \\
\hline Chew's scale (Chew) & $\mathrm{A}, \mathrm{B}, \mathrm{C}$ & 107 & $0-4$ & $\begin{array}{l}\text { M: } 1-3, \\
H: \geq 4\end{array}$ \\
\hline $\begin{array}{l}\text { Clinician-Rated Anticholinergic Scale } \\
\text { (CrAS) }\end{array}$ & A, B & 60 & $0-3$ & $\begin{array}{l}\text { M: } 1-2, \\
H: \geq 3\end{array}$ \\
\hline Durán’s scale (Durán) & $\mathrm{A}, \mathrm{B}$ & 100 & $0-2$ & $\begin{array}{l}\mathrm{M}: 1 \\
\mathrm{H}: \geq 2\end{array}$ \\
\hline
\end{tabular}

$M$ moderate burden, $H$ high burden

$A$ expert opinion, $B$ literature review/earlier versions of scales, $C$ serum anticholinergic activity/radioreceptor assay of anticholinergic activity

\section{Oral hygiene practices and oral hygiene status}

Both oral hygiene practices and oral hygiene status were used as outcomes in the current study. Oral hygiene practices were assessed with toothbrushing frequency and oral hygiene status with the number of teeth with visible dental plaque.

Toothbrushing and its frequency was determined with the dental survey, which included the question: "Do you brush your teeth" with the options of: "Very rarely/sometimes within a week/every now and then/once a day/twice a day/more than twice a day?" The answers were classified into two categories: toothbrushing at least twice a day vs. toothbrushing less than twice a day.

Dental plaque was assessed during the clinical oral examination. Before the actual examination the teeth were air-dried, but not professionally cleaned. Dental plaque was examined visually and with a probe from the buccal surface of each tooth, excluding 3 rd molars. If visible dental plaque was detected on the tooth's buccal surface, it was included in the number of teeth with dental plaque. In addition to continuous variable, dental plaque was also used as categorical variable:

$\left(\frac{\text { number of teeth with dental plaque }}{\text { number of teeth }}\right) * 100$

This variable was classified into two categories according to the distribution curve (the highest quarter): plenty of dental plaque ( $\geq 36 \%$ of teeth covered with dental plaque) vs. less dental plaque $(<36 \%$ of teeth covered with dental plaque).

\section{Potential confounding factors}

Sociodemographic factors were asked in the postal questionnaire. For the analyses, participant's education level was categorized into two categories: having a higher education (university level or equivalent) vs. having a lower education. Marital status was also categorized into two categories: being married/in an equivalent relationship vs. not married. Smoking was also asked in the postal questionnaire and it was categorized as non-smokers (never smokers and those who had quit) vs. current smokers.

Alcohol consumption was assessed according to participants' answers on questions related to alcohol drinking. The questions covered both consumption frequency and single time amounts of mild, moderate, and strong alcohol beverages. The answers were converted into pure alcohol consumption per day (g/day) and the WHO-recommended risk level for moderate alcohol consumption was used as the cut-off value (women $\geq 20 \mathrm{~g} /$ day and men $\geq 40 \mathrm{~g} /$ day) [25].

Information for mental health disorders (depression and psychosis) was gathered from medication data, the national prescription register, medical registers, and a 12-item General Health Questionnaire (GHQ-12) [26]. Participant's 
general diseases were verified from the postal questionnaire, the medical records, and official prescription registers. Six general diseases or disease groups were taken into account: congestive heart failure, coronary heart disease, diabetes (type I and II), rheumatic diseases (rheumatoid arthritis, Sjögren's syndrome, Polymyalgia rheumatica), epilepsy, and stroke. A number of general diseases were used in the analyses.

\section{Statistical methods}

Toothbrushing, as a categorical variable, and the number of teeth with dental plaque, as both continuous and categorical variable, were used as outcome variables. Due to the small number of participants with high anticholinergic burden, moderate and high anticholinergic burdens were combined into one category.

Relative risks (RR) with 95\% confidence intervals (CI) were estimated using a Poisson regression model with a robust variance estimation (categorical variables) and using a negative binominal regression model (continuous variables). The selection of potential confounders was based on the literature and all the analyses were adjusted for gender, marital status, education, alcohol consumption, smoking, use of removable prostheses, depression, psychosis, and general diseases. An offset variable (number of teeth) was used in the analyses for dental plaque. SPSS software (version 24.0, Chicago, IL, USA) was used in all the statistical analyses.

\section{Results}

All the participants $(n=1945)$ were $45-47$ years old at the time of the follow-up study and 54\% of them were women $(n=1041)$. Most of the participants were married or in equivalent relationship (76\%) and $27 \%$ of the participants had a higher education (university or equivalent). Characteristics of the whole study population are presented in Table 2 . The participants had on average 27 teeth ( \pm SD 2.1, 3rd molars excluded) and about $25 \%$ of the teeth had dental plaque on them (the median number of teeth with dental plaque was about seven) (Table 2). Thirty percent of the participants $(n=586)$ reported that they brush their teeth less than twice a day.

Seven hundred thirty-one participants $(38 \%)$ used at least one regular drug and 282 participants $(\sim 15 \%)$ used at least one anticholinergic drug included in the nine anticholinergic scales or had an anticholinergic burden. About $5 \%$ of the participants had moderate anticholinergic burden and only $1.5 \%$ of the participants had a high anticholinergic burden according to the scales.

The results of the univariate analyses are presented in Table 3 and the results of the multivariate regression analyses in Table 4. After adjustments for confounding factors, RRs for infrequent toothbrushing varied from 0.95 (ACB) to 1.11
(Durán) (Table 4). However, none of the RRs was statistically significant at the $p$ value level 0.05 (Table 4). With continuous anticholinergic burden, the RRs varied from 0.96 (ARS) to 1.08 (Durán).

Participants with anticholinergic burden had a higher likelihood of having more teeth with dental plaque than those without the burden (Table 4). RRs for the number of teeth with dental plaque were between 1.13 and 1.50 for categorical explanatory variables; for continuous explanatory variables, RRs were between 1.03 and 1.13. The strongest association was when anticholinergic burden was measured with the AAS and Chew's scale (RR: 1.50, CI: 1.16-1.96; RR: 1.36, CI: 1.10-1.68, respectively). With continuous anticholinergic burden, AAS and ACB (RR: 1.13, CI: 1.02-1.24, RR: 1.12, CI: 1.00-1.24, respectively) were associated with the number of teeth with dental plaque (Table 4). The results using categorical measure for dental plaque did not differ significantly and are presented in the Table 4.

Additional analyses were also done using a population where participants with psychiatric diseases were excluded. The results of those analyses where participants with psychiatric diseases were excluded did not essentially differ from those obtained in the main analyses.

\section{Discussion}

It appears that anticholinergic burden is associated with poor oral hygiene status, but not with oral hygiene practices.

Anticholinergic drugs could affect oral hygiene in several ways. Firstly, it can be speculated that the anticholinergic burden decreases participant motivation and ability to remember to brush their teeth twice a day due to a decline in cognitive functions [9]. Secondly, anticholinergic burden may lead to insufficient removal of dental plaque by lowering the patient's attention and precision required to carry out efficient toothbrushing [27]. Thirdly, it could also be speculated that the effects of anticholinergic burden on oral hygiene are mediated by hyposalivation, which is thought to promote the development of dental plaque by diminishing bacterial clearance from the oral cavity, by increasing bacterial adherence to hard and soft tissues, and by reducing anti-bacterial effects of saliva [28]. It should be emphasized that the current evidence on the topic of hyposalivation is inconclusive, as there are studies both for [29-32] and against [33, 34].

A major strength of the study was the large, unselected population with an acceptable participation rate $(61.7 \%)$, which meant that the study population was a good representation of this age-group living in Northern Finland. On the other hand, it should also be kept in mind that despite the fairly good participation rate, $38 \%$ drop-out of participants from the 
Table 2 Characteristics of the study population

\begin{tabular}{|c|c|c|}
\hline Variable & All participants & Anticholinergic burden \\
\hline$n$ & 1945 & 282 \\
\hline Gender, proportion of women, $n(\%)$ & $1041(54)$ & $183(65)$ \\
\hline Married or equivalent relationship, $n(\%)$ & $1482(76)^{\mathrm{a}}$ & $195(69)^{\mathrm{a}}$ \\
\hline Higher education (university or equivalent), $n(\%)$ & $533(27)^{\mathrm{b}}$ & $60(21)^{\mathrm{b}}$ \\
\hline Current smoker, $n(\%)$ & $424(22)$ & $79(28)$ \\
\hline Moderate alcohol consumption risk, $n(\%)$ & $182(9.4)^{\mathrm{c}}$ & $35(12)^{\mathrm{c}}$ \\
\hline Diagnosed depression or depressive symptoms, $n(\%)$ & $145(7.5)$ & $66(23)$ \\
\hline Diagnosed psychosis, $n(\%)$ & $30(1.5)^{\mathrm{d}}$ & $23(8.0)^{\mathrm{d}}$ \\
\hline One or more general diseases, $n(\%)$ & $174(9.0)$ & $87(31)$ \\
\hline Epilepsy, $n(\%)$ & $26(1.3)$ & $16(5.7)$ \\
\hline Coronary heart disease & $19(1.0)$ & $7(2.5)$ \\
\hline Congestive heart failure & $8(0.4)$ & $6(2.1)$ \\
\hline Stroke & $18(0.9)$ & $9(3.2)$ \\
\hline Rheumatic disease & $52(2.7)$ & $26(9.2)$ \\
\hline Diabetes & $67(3.4)$ & $37(13)$ \\
\hline Total number or drugs, median (IQR) & $0(0-1)$ & $2(1-3)$ \\
\hline Participants using at least one regular drug, $n(\%)$ & $731(38)$ & $282(100)$ \\
\hline Using at least one anticholinergic drug, $n(\%)$ & $282(15)$ & $282(100)$ \\
\hline \multicolumn{3}{|l|}{ Anticholinergic Activity Scale, $n(\%)$} \\
\hline$\geq 1$ & $106(5.4)$ & $106(38)$ \\
\hline \multicolumn{3}{|l|}{ Anticholinergic Burden Classification, $n(\%)$} \\
\hline$\geq 1$ & $36(1.8)$ & $36(13)$ \\
\hline \multicolumn{3}{|l|}{ Anticholinergic Cognitive Burden Scale, $n(\%)$} \\
\hline$\geq 1$ & $123(6.3)$ & $123(44)$ \\
\hline \multicolumn{3}{|l|}{ Anticholinergic Drug Scale, $n(\%)$} \\
\hline$\geq 1$ & $153(7.9)$ & $153(54)$ \\
\hline \multicolumn{3}{|l|}{ Anticholinergic Load Scale, $n(\%)$} \\
\hline$\geq 1$ & $180(9.3)$ & $180(64)$ \\
\hline \multicolumn{3}{|l|}{ Anticholinergic Risk Scale, $n(\%)$} \\
\hline$\geq 1$ & $73(3.7)$ & $73(26)$ \\
\hline \multicolumn{3}{|l|}{ Chew's scale, $n(\%)$} \\
\hline$\geq 1$ & $168(8.7)$ & $168(60)$ \\
\hline \multicolumn{3}{|l|}{ Clinician-Rated Anticholinergic Scale, $n(\%)$} \\
\hline$\geq 1$ & $118(6.0)$ & $118(42)$ \\
\hline \multicolumn{3}{|l|}{ Durán’s scale, $n(\%)$} \\
\hline$\geq 1$ & $139(7.1)$ & $139(49)$ \\
\hline Number of teeth (excluding 3rd molars), mean $( \pm \mathrm{SD})$ & $27(2.1)$ & $26(2.0)$ \\
\hline Using a removable prosthesis, $n(\%)$ & $19(1.0)$ & $6(2)$ \\
\hline Number of teeth with dental plaque, median (IQR) & $6.6(1-10)^{\mathrm{e}}$ & $7.5(1-11)^{\mathrm{e}}$ \\
\hline Percentage of teeth covered with dental plaque, on average & 24 & 29 \\
\hline Toothbrushing less than twice a day, $n(\%)$ & $586(30)^{\mathrm{a}}$ & $84(30)^{\mathrm{a}}$ \\
\hline
\end{tabular}

$S D$ standard deviation, $I Q R$ inter quartile range

a $56 / 11$ missing

b 80/14 missing

c $55 / 9$ missing

d 64/9 missing

e $11 / 4$ missing 
Table 3 Unadjusted associations between independent variables and oral hygiene

\begin{tabular}{|c|c|c|c|}
\hline Variables & $\begin{array}{l}\text { Number of teeth with dental plaque } \\
(\mathrm{RR}, \mathrm{CI} 95 \%)^{\mathrm{a}}\end{array}$ & $\begin{array}{l}\text { Toothbrushing less than twice a day } \\
(\text { RR, CI 95\%) }\end{array}$ & $\begin{array}{l}\text { Plenty of dental plaque } \\
(\mathrm{RR}, \mathrm{CI} 95 \%)^{\mathrm{a}}\end{array}$ \\
\hline \multicolumn{4}{|l|}{ Gender } \\
\hline Women & 1.0 & 1.0 & 1.0 \\
\hline Men & $1.41(1.29-1.55)$ & $2.51(2.15-2.92)$ & $1.76(1.05-2.06)$ \\
\hline \multicolumn{4}{|l|}{ Married or equivalent relationship } \\
\hline Yes & 1.0 & 1.0 & 1.0 \\
\hline No & $1.09(0.98-1.23)$ & $1.29(1.11-1.51)$ & $1.05(0.87-1.26)$ \\
\hline \multicolumn{4}{|l|}{ Higher education (university or equivalent) } \\
\hline Yes & 1.0 & 1.0 & 1.0 \\
\hline No & $1.15(1.02-1.30)$ & $1.97(1.61-2.39)$ & $1.28(1.06-1.55)$ \\
\hline \multicolumn{4}{|l|}{ Current smoker } \\
\hline No & 1.0 & 1.0 & 1.0 \\
\hline Yes & $1.22(1.10-1.36)$ & $1.38(1.19-1.60)$ & $1.45(1.24-1.71)$ \\
\hline \multicolumn{4}{|l|}{ Moderate alcohol consumption risk ${ }^{\mathrm{b}}$} \\
\hline No & 1.0 & 1.0 & 1.0 \\
\hline Yes & $1.22(1.04-1.42)$ & $1.13(0.91-1.41)$ & $1.46(1.18-1.81)$ \\
\hline Number of general diseases (continuous) & $1.23(1.04-1.44)$ & $1.26(1.07-1.49)$ & $1.31(1.16-1.48)$ \\
\hline \multicolumn{4}{|c|}{ Diagnosed depression or depressive symptoms } \\
\hline No & 1.0 & 1.0 & 1.0 \\
\hline Yes & $1.08(0.92-1.28)$ & $0.99(0.76-1.30)$ & $1.12(0.86-1.47)$ \\
\hline \multicolumn{4}{|l|}{ Diagnosed psychosis } \\
\hline No & 1.0 & 1.0 & 1.0 \\
\hline Yes & $1.91(1.45-2.52)$ & $1.53(1.02-2.29)$ & $2.35(1.72-3.23)$ \\
\hline \multicolumn{4}{|l|}{ Using removable prothesis } \\
\hline No & 1.0 & 1.0 & 1.0 \\
\hline Yes & $1.99(1.45-2.72)$ & $1.99(1.37-2.90)$ & $2.87(2.13-3.86)$ \\
\hline \multicolumn{4}{|l|}{ Anticholinergic Activity Scale } \\
\hline 0 & 1.0 & 1.0 & 1.0 \\
\hline$\geq 1$ & $1.58(1.24-2.02)$ & $1.13(0.84-1.52)$ & $1.52(1.17-1.97)$ \\
\hline Continuous & $1.14(1.06-1.21)$ & $1.04(0.94-1.14)$ & $1.13(1.04-1.22)$ \\
\hline \multicolumn{4}{|l|}{ Anticholinergic Burden Classification } \\
\hline 0 & 1.0 & 1.0 & 1.0 \\
\hline$\geq 1$ & $1.29(0.85-1.93)$ & $1.19(0.75-1.88)$ & $1.74(1.03-2.94)$ \\
\hline Continuous & $1.09(0.99-1.20)$ & $1.04(0.88-1.23)$ & $1.15(0.99-1.33)$ \\
\hline \multicolumn{4}{|l|}{ Anticholinergic Cognitive Burden } \\
\hline 0 & 1.0 & 1.0 & 1.0 \\
\hline$\geq 1$ & $1.37(1.09-1.71)$ & $1.11(0.85-1.46)$ & $1.38(1.06-1.79)$ \\
\hline Continuous & $1.16(1.09-1.24)$ & $1.05(0.95-1.16)$ & $1.17(1.08-1.27)$ \\
\hline \multicolumn{4}{|l|}{ Anticholinergic Drug Scale } \\
\hline 0 & 1.0 & 1.0 & 1.0 \\
\hline$\geq 1$ & $1.32(1.07-1.62)$ & $1.14(0.89-1.46)$ & $1.29(1.00-1.64)$ \\
\hline Continuous & $1.13(1.05-1.21)$ & $1.06(0.96-1.16)$ & $1.13(1.03-1.23)$ \\
\hline \multicolumn{4}{|l|}{ Anticholinergic Load Scale } \\
\hline 0 & 1.0 & 1.0 & 1.0 \\
\hline$\geq 1$ & $1.25(1.03-1.51)$ & $1.13(0.90-1.42)$ & $1.26(1.00-1.59)$ \\
\hline Continuous & $1.08(0.99-1.18)$ & $1.04(0.93-1.17)$ & $1.07(0.95-1.21)$ \\
\hline \multicolumn{4}{|l|}{ Anticholinergic Risk Scale } \\
\hline 0 & 1.0 & 1.0 & 1.0 \\
\hline$\geq 1$ & $1.45(1.09-1.92)$ & $1.16(0.83-1.62)$ & $1.39(1.01-1.93)$ \\
\hline Continuous & $1.12(1.09-1.23)$ & $1.02(0.88-1.17)$ & $1.09(0.96-1.24)$ \\
\hline \multicolumn{4}{|l|}{ Chew's scale } \\
\hline 0 & 1.0 & 1.0 & 1.0 \\
\hline$\geq 1$ & $1.51(1.24-1.84)$ & $1.22(0.97-1.53)$ & $1.46(1.17-1.82)$ \\
\hline Continuous & $1.11(1.04-1.18)$ & $1.05(0.97-1.14)$ & $1.09(1.01-1.18)$ \\
\hline \multicolumn{4}{|l|}{ Clinician-Rated Anticholinergic Scale } \\
\hline 0 & 1.0 & 1.0 & 1.0 \\
\hline$\geq 1$ & $1.32(1.04-1.66)$ & $1.15(0.88-1.50)$ & $1.33(1.01-1.74)$ \\
\hline Continuous & $1.13(1.04-1.23)$ & $1.02(0.90-1.14)$ & $1.12(1.01-1.25)$ \\
\hline Durán's scale & & & \\
\hline 0 & 1.0 & 1.0 & 1.0 \\
\hline$\geq 1$ & $1.27(1.03-1.58)$ & $1.16(0.90-1.50)$ & $1.20(0.92-1.57)$ \\
\hline Continuous & $1.13(1.03-1.25)$ & $1.10(0.98-1.24)$ & $1.11(0.97-1.27)$ \\
\hline
\end{tabular}

${ }^{\text {a }}$ Data presented as a relative risk (RR) with $95 \%$ confidence intervals (CI 95\%)

${ }^{\mathrm{b}}$ Moderate risk for alcohol consumption: $\geq 20 \mathrm{~g}$ of pure ethanol/day (women), $\geq 40 \mathrm{~g}$ of pure ethanol/day (men) 
Table 4 Adjusted associations between anticholinergic scales and oral hygiene

\begin{tabular}{|c|c|c|c|}
\hline Anticholinergic Scale & $\begin{array}{l}\text { Number of teeth with dental plaque } \\
(\mathrm{RR}, \mathrm{CI} 95 \%)^{\mathrm{a}}\end{array}$ & $\begin{array}{l}\text { Toothbrushing less than twice a day } \\
(\text { RR, CI 95\%) }\end{array}$ & $\begin{array}{l}\text { Plenty of dental plaque } \\
(\mathrm{RR}, \mathrm{CI} 95 \%)^{\mathrm{a}}\end{array}$ \\
\hline \multicolumn{4}{|c|}{ Anticholinergic Activity Scale } \\
\hline 0 & 1.0 & 1.0 & 1.0 \\
\hline$\geq 1$ & $1.50(1.16-1.94)^{*}$ & $1.09(0.81-1.48)$ & $1.51(1.11-2.06)^{*}$ \\
\hline Continuous & $1.13(1.02-1.24)^{*}$ & $1.02(0.92-1.15)$ & $1.09(0.97-1.21)$ \\
\hline \multicolumn{4}{|c|}{ Anticholinergic Burden Classification } \\
\hline 0 & 1.0 & 1.0 & 1.0 \\
\hline$\geq 1$ & $1.17(0.78-1.75)$ & $1.04(0.63-1.72)$ & $1.15(0.70-1.88)$ \\
\hline Continuous & $1.08(0.93-1.24)$ & $1.03(0.86-1.23)$ & $1.10(0.94-1.27)$ \\
\hline \multicolumn{4}{|c|}{ Anticholinergic Cognitive Burden } \\
\hline 0 & 1.0 & 1.0 & 1.0 \\
\hline$\geq 1$ & $1.24(0.97-1.57)$ & $0.95(0.71-1.26)$ & $1.15(0.85-1.57)$ \\
\hline Continuous & $1.12(1.00-1.24)^{*}$ & $0.98(0.86-1.10)$ & $1.08(0.97-1.21)$ \\
\hline \multicolumn{4}{|c|}{ Anticholinergic Drug Scale } \\
\hline 0 & 1.0 & 1.0 & 1.0 \\
\hline$\geq 1$ & $1.22(0.98-1.52)$ & $1.09(0.84-1.40)$ & $1.20(0.90-1.59)$ \\
\hline Continuous & $1.09(0.98-1.23)$ & $1.02(0.91-1.15)$ & $1.04(0.92-1.18)$ \\
\hline \multicolumn{4}{|c|}{ Anticholinergic Load Scale } \\
\hline 0 & 1.0 & 1.0 & 1.0 \\
\hline$\geq 1$ & $1.13(0.93-1.39)$ & $1.07(0.83-1.36)$ & $1.17(0.90-1.54)$ \\
\hline Continuous & $1.03(0.92-1.15)$ & $1.03(0.91-1.17)$ & $1.00(0.87-1.15)$ \\
\hline \multicolumn{4}{|c|}{ Anticholinergic Risk Scale } \\
\hline 0 & 1.0 & 1.0 & 1.0 \\
\hline$\geq 1$ & $1.25(0.92-1.71)$ & $1.00(0.70-1.43)$ & $1.01(0.68-1.50)$ \\
\hline Continuous & $1.03(0.90-1.18)$ & $0.96(0.82-1.13)$ & $0.97(0.84-1.13)$ \\
\hline \multicolumn{4}{|l|}{ Chew's scale } \\
\hline 0 & 1.0 & 1.0 & 1.0 \\
\hline$\geq 1$ & $1.36(1.10-1.68)^{*}$ & $1.06(0.82-1.35)$ & $1.36(1.04-1.78)^{*}$ \\
\hline Continuous & $1.08(0.99-1.18)$ & $1.04(0.94-1.16)$ & $1.03(0.93-1.14)$ \\
\hline \multicolumn{4}{|c|}{ Clinician-Rated Anticholinergic Scale } \\
\hline 0 & 1.0 & 1.0 & 1.0 \\
\hline$\geq 1$ & $1.19(0.93-1.52)$ & $1.07(0.81-1.42)$ & $1.13(0.83-1.54)$ \\
\hline Continuous & $1.07(0.96-1.20)$ & $0.97(0.86-1.09)$ & $1.03(0.92-1.17)$ \\
\hline \multicolumn{4}{|l|}{ Durán’s scale } \\
\hline 0 & 1.0 & 1.0 & 1.0 \\
\hline$\geq 1$ & $1.18(0.94-1.49)$ & $1.11(0.84-1.46)$ & $1.02(0.75-1.40)$ \\
\hline Continuous & $1.08(0.93-1.24)$ & $1.08(0.94-1.25)$ & $0.99(0.85-1.15)$ \\
\hline
\end{tabular}

${ }^{\mathrm{a}}$ Data presented as a relative risk (RR) with $95 \%$ confidence intervals (CI 95\%)

$* p<0.05$

All the models were adjusted for gender, marital status, education, alcohol consumption, smoking, the use of removable prostheses, depression, psychosis, and general diseases. In addition, the number of teeth was used as an off-set variable in the analyses for dental plaque

clinical oral examination may have led to sample selection bias.

Another strength of the present study was the use of two outcomes: self-reported toothbrushing and the presence of dental plaque. In this population, there were discrepancies between the self-reported toothbrushing frequency and the presence of dental plaque, potentially indicating a high risk of social desirability bias related to the toothbrushing variable. It is self-evident that the dental plaque variable provides more accurate information about the level of oral hygiene.

The assessment of regular drug use can also be seen as one of the strengths of this study. The use of drugs during the years 
2012 and 2013 was determined by combining self-reported drug use and drug purchase information from the National Prescription Register. Despite this comprehensive approach, there are factors, such as non-adherence, that cannot be entirely excluded. However, previous studies have shown that the quantification method used is sufficient for the present study $[35,36]$.

The disadvantage of this population was that there was a fairly small number of participants with anticholinergic burden. It can be speculated that the associations would be easily detectable in a population with a higher drug usage, but - at the same time - the risk of possible confounding due to comorbidities would most likely be high.

As suggested by a recent review [37], anticholinergic burden in the present study was measured by using several anticholinergic scales in order to increase comparability with other studies. The rationale for this approach is the considerable variation between individual anticholinergic scales, for example in the inclusion and ranking of anticholinergic drugs [23, 37]. It should be kept in mind that there are also certain limitations in the anticholinergic scales. The scales assume that pharmacological mechanisms are simple and that all the drugs have a linearly additive anticholinergic effect [23]. Furthermore, the scales ignore intrinsic factors such as pharmacokinetics and susceptibility to anticholinergic effects [37]. None of the scales used takes drug dosage into account. Despite the aforementioned, the anticholinergic scales used are so far the best available method to measure anticholinergic burden.

Although multiple potential confounding factors were taken into account, it is still possible that other, uncontrolled factors confound the association between anticholinergic burden and oral hygiene. These could be behavioural factors, such as diet, or conditions effecting indirectly oral hygiene via hyposalivation such as the radiotherapy of the head and neck region, for example. It should also be kept in mind that medical conditions as a cause of anticholinergic drug use may also affect oral hygiene. On the other hand, it can be speculated that these effects may not have essential biasing effect due to the fact that major medical conditions were taken into account in the analyses. In complementary analyses, it was observed that the exclusion of participants with psychiatric diseases did not change the results essentially (data not shown).

From a clinical perspective, the findings stress the importance of providing oral hygiene instructions to patients taking anticholinergic drugs. In addition to having a dry mouth, these patients seem to be at a higher risk of having poor oral hygiene. A combination of these conditions can have serious harmful effects on oral health and thus, dental professionals should always give instructions to this patient group on how to achieve sufficient oral hygiene and how to manage with dry mouth and its symptoms. It should also be kept in mind that the need for other prophylactic measures (i.e. additional fluoride) is high among patients with dry mouth.

\section{Conclusion}

Anticholinergic burden is associated with poor oral hygiene.

Acknowledgments The authors would like to thank the late Prof. Paula Rantakallio (launch of NFBC 1966), the participants of the 46-year study, and the NFBC project centre.

Funding information Open access funding provided by University of Oulu including Oulu University Hospital. The NFBC1966 received financial support from the University of Oulu (No. 24000692), Oulu University Hospital (No. 24301140), and the ERDF European Regional Development Fund (No. 539/2010 A31592). A.T. received a personal grant from the Finnish Dental Association Apollonia for the current study.

\section{Compliance with ethical standards}

Conflict of interest The authors declare that they have no conflict of interest.

Ethical approval All procedures performed in the studies involving human participants were in accordance with the ethical standards of the institutional Ethical Committee of the Northern Ostrobothnia Hospital District (2/2012) and with the 1964 Declaration of Helsinki and its later amendments or comparable ethical standards.

Informed consent Informed consent was obtained from all individual participants included in the study.

Open Access This article is licensed under a Creative Commons Attribution 4.0 International License, which permits use, sharing, adaptation, distribution and reproduction in any medium or format, as long as you give appropriate credit to the original author(s) and the source, provide a link to the Creative Commons licence, and indicate if changes were made. The images or other third party material in this article are included in the article's Creative Commons licence, unless indicated otherwise in a credit line to the material. If material is not included in the article's Creative Commons licence and your intended use is not permitted by statutory regulation or exceeds the permitted use, you will need to obtain permission directly from the copyright holder. To view a copy of this licence, visit http://creativecommons.org/licenses/by/4.0/.

\section{References}

1. Jepsen S, Blanco J, Buchalla WC et al (2017) Prevention and control of dental caries and periodontal diseases at individual and population level: consensus report of group 3 of joint EFP/ORCA workshop on the boundaries between caries and periodontal diseases. J Clin Periodontol 44(Suppl 18):S85-S93

2. Maes L, Vereecken C, Vanobbergen J, Honkala S (2006) Tooth brushing and social characteristics of families in 32 countries. Int Dent J 56(3):159-167

3. Christensen LB, Petersen PE, Krustrup U, Kjoller M (2003) Selfreported oral hygiene practices among adults in Denmark. Community Dent Health 20(4):229-235

4. Tanner T, Päkkilä J, Karjalainen K, Kämppi A, Järvelin MR, Patinen P, Tjäderhane L, Anttonen V (2015) Smoking, alcohol use, socioeconomic background and oral health among young Finnish adults. Community Dent Oral Epidemiol 43(5):406-414 
5. Anttila S, Knuuttila M, Ylöstalo P, Joukomaa M (2006) Symptoms of depression and anxiety in relation to dental health behavior and selfperceived dental treatment need. Eur J Oral Sci 114(2):109-114

6. Chu KY, Yang NP, Chou P, Chiu HJ, Hsien J, Chi LY (2010) Factors associated with dental caries among institutionalized residents with schizophrenia in Taiwan: a cross-sectional study. BMC Public Health 10:482. https://doi.org/10.1186/1471-2458-10-482

7. Tiisanoja A, Syrjälä AM, Komulainen K, Hartikainen S, Taipale H, Knuuttila M, Ylöstalo P (2018) The association of medications with sedative properties with oral health behaviour in communitydwelling older people. Int J Dent Hyg 16(2):e17-e22

8. Plemons JM, Al-Hashimi I, Marek CL (2014) Managing xerostomia and salivary gland hypofunction: executive summary of a report from the American Dental Association Council on Scientific Affairs. J Am Dent Assoc 145(8):867-873

9. Salahudeen M, Dufful S, Nistala P (2015) Anticholinergic burden quantified by anticholinergic risk scales and adverse outcome in older people: a systemic review. BMC Geriatr 15:31. https://doi. org/10.1186/s12877-015-0029-9

10. Ziad A, Olekhnovitch R, Ruiz F, Berr C, Bégaud B, Goldberg M, Zins M, Mura T (2018) Anticholinergic drug use and cognitive performances in middle age: findings from the CONSTANCES cohort. J Neurol Neurosurg Psychiatry 89(10):1107-1115

11. Tiisanoja A, Syrjälä AH, Kullaa A, Ylöstalo P (2019) Anticholinergic burden and dry mouth in middle-aged people. JDR Clin Trans Res 5(1):62-70

12. Rantakallio P (1988) The longitudinal study of the Northern Finland Birth Cohort of 1966. Paediatr Perinat Epidemiol 2(1): 59-88

13. World Health Organization (2018) WHO Collaborating Centre for Drug Statistic Methodology: the anatomical therapeutic chemical classification system http://www.whocc.no/atc_ddd_index/. Accessed 20 March 2019

14. Ehrt U, Broich K, Larsen JP, Ballard C, Aarsland D (2010) Use of drugs with anticholinergic effect and impact on cognition in Parkinson's disease: a cohort study. J Neurol Neurosurg Psychiatry 81(2):160-165

15. Ancelin ML, Artero S, Portet F, Dupuy AM, Touchon J, Ritchie K (2006) Non-degenerative mild cognitive impairment in elderly people and use of anticholinergic drugs: longitudinal cohort study. BMJ 332(7539):455-459

16. Campbell NL, Maidment I, Fox C, Kahn B, Boustani M (2013) The 2012 update to the Anticholinergic Cognitive Burden Scale. J Am Geriatr Soc 61(Suppl 1):S142-S143

17. Carnahan RM, Lund BC, Perry PJ, Pollock BG, Culp KR (2006) The Anticholinergic Drug Scale as a measure of drug-related anticholinergic burden: associations with serum anticholinergic activity. J Clin Pharmacol 46(12):1481-1486

18. Sittironnarit G, Ames D, Bush A, Faux N, Flicker L, Foster J, Hilmer S, Lautenschlager NT, Maruff P, Masters CL, Martins RN, Rowe C, Szoeke C, Ellis KA, AIBL research group (2011) Effects of anticholinergic drugs on cognitive function in older Australians: results from the AIBL study. Dement Geriatr Cogn Disord 31(3): 173-178

19. Rudolph JL, Salow MJ, Angelini MC, McGlinchey RE (2008) The anticholinergic risk scale and anticholinergic adverse effects in older persons. Arch Intern Med 168(5):508-513

20. Chew ML, Mulsant BH, Pollock BG, Lehman ME, Greenspan A, Mahmoud RA, Kirshner MA, Sorisio DA, Bies RR, Gharabawi G (2008) Anticholinergic activity of 107 medications commonly used by older adults. J Am Geriatr Soc 56(7):1333-1341

21. Han L, Agostini JV, Allore HG, Abrahamowicz M, Primeau F, Élie M (2008) Cumulative anticholinergic exposure is associated with poor memory and executive function in older men. J Am Geriatr Soc 56(12):2203-2210
22. Durán CE, Azermai M, Vander Stichele RH (2013) Systematic review of anticholinergic risk scales in older adults. Eur J Clin Pharmacol 69(7):1485-1496

23. Villalba-Moreno AM, Alfaro-Lara ER, Pérez-Guerrero MC, NietoMartín MD, Santos-Ramos B (2016) Systematic review on the use of anticholinergic scales in poly pathological patients. Arch Gerontol Geriatr 62:1-8

24. Alaraudanjoki V, Laitala ML, Tjäderhane L, Pesonen P, Lussi A, Ronkainen J, Anttonen V (2016) Influence of intrinsic factors on erosive tooth wear in a large-scale epidemiological study. Caries Res 50(5):508-516

25. World Health Organization (2000) International guide for monitoring alcohol consumption and related harm. Geneva, Switzerland. http://whqlibdoc.who.int/hq/2000/WHO MSD MSB 00.4.pdf. Accessed 24 March 2019

26. Goldberg D, Hillier V (1979) A scaled version of the General Health Questionnaire. Psychol Med 9(1):139-145

27. Hayasaki H, Saitoh I, Nakakura-Ohshima K, Hanasaki M, Nogami Y, Nakajima T, Inada E, Iwasaki T, Iwase Y, Sawami T, Kawasaki K, Murakami N, Murakami T, Kurosawa M, Kimi M, Kagoshima A, Soda M, Yamasaki Y (2014) Tooth brushing for oral prophylaxis. Jap Dent Sci Rev 50(3):69-77

28. Dawes C, Pedersen AM, Villa AD et al (2015) The functions of human saliva: a review sponsored by the world workshop on oral medicine VI. Arch Oral Biol 60(6):863-874

29. Márton K, Madléna M, Bánóczy J, Varga G, Fejérdy P, Sreebny LM, Nagy G (2008) Unstimulated whole saliva flow rate in relation to sicca symptoms in Hungary. Oral Dis 14(5):472-477

30. Antoniazzi RP, Miranda LA, Zanatta FB, Islabao AG, Gustafsson A, Chiapinotto GA, Oppermann RV (2009) Periodontal conditions of individuals with Sjogren's syndrome. J Periodontol 80(3):429435

31. Syrjälä AM, Raatikainen L, Komulainen K, Knuuttila M, Ruoppi P, Hartikainen S, Sulkava R, Ylöstalo P (2011) Salivary flow rate and periodontal infection - a study among subjects aged 75 years or older. Oral Dis 17(4):387-392

32. Mizutani S, Ekuni D, Tomofuji T, Azuma T, Kataoka K, Yamane M, Iwasaki Y, Morita M (2015) Relationship between xerostomia and gingival condition in young adults. J Periodontal Res 50(1):74 79

33. Markitziu A, Zafiropoulos G, Tsalikis L, Cohen L (1992) Gingival health and salivary function in head and neck-irradiated patients. Oral Surg Oral Med Oral Pathol 73(4):427-433

34. Idrees M, Nassani M, Kujan O (2018) Assessing the association between unstimulated whole salivary flow rate (UWSFR) and oral health status among healthy adult subjects: a cross-sectional study. Med Oral Patol Oral Cir Bucal 23(4):e384-e390

35. Furu K, Wettermark B, Andersson M, Martikainen JE, Almasdottir AB, Sorensen HAT (2010) The Nordic countries as a cohort for pharmacoepidemiological research. Basic Clin Pharmacol Toxicol 106(2):86-94

36. Haapea M, Miettunen J, Lindeman S, Joukamaa M, Koponen H (2010) Agreement between self-reported and pharmacy data on medication use in the Northern Finland 1966 Birth Cohort. Int J Methods Psychiatr Res 19(2):88-96

37. Mayer T, Haefeli WE, Seidling HM (2015) Different methods, different results - how do available methods link a patient's anticholinergic load with adverse outcomes? Eur J Clin Pharmacol 71(11): $1299-1314$

Publisher's note Springer Nature remains neutral with regard to jurisdictional claims in published maps and institutional affiliations. 